RESENHA

\title{
Conhecimento, inovação e território
}

\section{Mário Vale}

Lisboa, Portugal: Editora Papagaio, 128 p., 2012.

\section{Regina Tunes*}

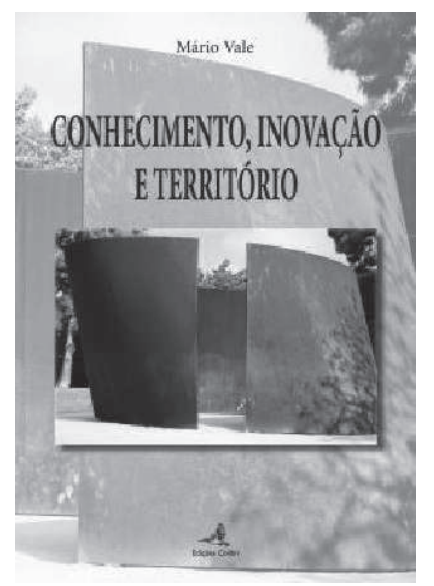

Conhecimento, inovação e território, de autoria de Mário Vale, pesquisador do Centro de Estudos Geográficos do Instituto de Letras e professor do Instituto de Geografia e Ordenamento do Território da Universidade de Lisboa, tem como principal objetivo discutir as transformações econômicas nas escalas local e regional relacionadas à sociedade e à economia do conhecimento. Tais transformações econômicas fizeram emergir a discussão das territorialidades e do papel da aglomeração espacial no desenvolvimento das atividades de inovação e conhecimento.

O livro tem uma contribuição importante na área de geografia da inovação, pois é uma das primeiras obras que faz uma sistematização das teorias e abordagens que procuram compreender a relação entre geografia, território e inovação. A preocupação fundamental desses estudos é analisar as condicionantes que acarretam a concentração geográfica das atividades que envolvem o processo de inovação, culminando, em alguns casos, com a territorialização do processo inovador.

Nesse sentido, a questão que norteia a obra é: quais são os fatores que contribuem para esta concentração geográfica em uma fase do capitalismo marcada pela mobilidade do capital e da informação e de redução relativa dos custos de transportes? A questão central do livro já dá indícios sobre a perspectiva teórico-metodológica que o autor percorrerá ao longo da obra. Mário Vale, assim como vários outros

* Universidade de São Paulo (USP), São Paulo (SP), Brasil. Email: rtunes@usp.br 
pesquisadores na área de geografia da inovação na Europa, tais como Denis Maillat, Olivier Crevoisier, Philippe Aydalot e Roberto Camagni, parte da perspectiva de que o processo de globalização, longe de sua pretensa homogeneização de espaços e paisagens, promove, de forma contraditória, a fragmentação do espaço e o reforço das condições desiguais de desenvolvimento.

Assim, o autor aponta três ordens de razão para a concentração geográfica da inovação e discorre, nos cinco capítulos que compõem o livro, mais detalhes sobre sua visão.

O livro procura responder a esta questão central, assumindo que há três ordens de razão para esta concentração geográfica: razões de ordem produtiva (sistema produtivo); razôes de ordem laboral (mercado de trabalho); razões de ordem tecnológica (aprendizagem e inovação) (VALE, 2012, p. 11).

No primeiro caso, das razôes de ordem produtiva relacionadas à concentração geográfica da inovação, o autor aborda as questôes que envolvem as redes de relações entre as empresas, configurando-se "redes de inovação" por meio de subcontratações e terceirizaçōes da produção, que complementam o processo produtivo fora da grande empresa.

Já no que se refere às razões ligadas ao mercado laboral, o autor faz uma análise sobre a relação entre a qualificação da mão de obra, a criatividade presente em grandes centros urbanos, como Lisboa que é o centro urbano analisado pelo autor, e a produção de espaços relacionados à inovação. $\mathrm{O}$ autor exemplifica, nesse caso, sua abordagem com a análise específica de um espaço criativo e inovador na cidade de Lisboa que é o LX Factory, uma área decadente do ponto de vista industrial na década de 1970, no centro de Lisboa, que foi transformada em espaço de pequenos negócios criativos que atraíram outros investimentos para a região, promovendo, além da inovação, uma revitalização urbana importante.

O terceiro ponto, as razões de ordem tecnológica, corresponde às relações entre território, conhecimento e os processos de aprendizagem que, segundo o autor, são dependentes de contextos espaciais específicos e são impulsionados em locais onde o conhecimento tácito, aquele que não está formalmente organizado e disponível para acesso distante, é produzido e circula informalmente entre as pessoas que frequentam esses ambientes. Dado o seu caráter intensamente informal e dependente das relações locais de aprendizagem, o autor faz uma relação entre esse tipo de conhecimento e a importância do território e da localização. 
A partir desses pressupostos, a obra está organizada em cinco capítulos que partem de uma análise mais teórico-metodológica, nos primeiros, para a análise empírica do caso português, nos últimos.

No capítulo 1, o autor discorre sobre o papel das inovações no desenvolvimento regional, afirmando que a inovação é uma dimensão econômica do desenvolvimento que marca a modernidade. Segundo Mário Vale, essa perspectiva iniciou-se nas formas de organização econômica e social baseadas nas experiências europeia e norte-americana a partir dos anos 1970 e estão vinculadas ao processo de reestruturação produtiva mundial.

Ainda nesse capítulo inicial, o autor também faz uma análise dos primeiros trabalhos que abordaram a relação entre inovação e desenvolvimento, destacando a obra pioneira de Schumpeter (1911), na economia, e de Hagerstrand (1967), na geografia.

Já no capítulo 2, intitulado de "Teorias tradicionais de desenvolvimento regional", o autor analisa cinco famílias teóricas diferentes no estudo do desenvolvimento regional: a teoria da economia clássica; as abordagens keynesianas; a teoria marxista; o desenvolvimento endógeno e o capital social; e, por último, a contribuição do que ele identificou como a "nova geografia econômica".

Nas duas primeiras famílias teóricas, Mário Vale destaca a dualidade entre elas acerca do papel do Estado. Enquanto a teoria clássica acreditava que a maturidade do processo de desenvolvimento levaria a um natural decréscimo do desenvolvimento regional desigual, daí não ter relevância alguma a intervenção do Estado na economia, a segunda destaca o importante papel do Estado por meio dos investimentos públicos na geração de empregos e riquezas que corroboram com o desenvolvimento.

A terceira família teórica sobre desenvolvimento regional analisada pelo autor foi a teoria marxista, em que ele destaca três perspectivas fundamentais dessa abordagem: o conceito de spatial fix de David Harvey (2007); a teoria da dependência dos autores ligados à Cepal (Comissão Econômica para a América Latina e Caribe); e a teoria centro-periferia de Wallerstein (1974).

A quarta e quinta famílias teóricas, mais recentes, estão associadas respectivamente ao paradigma do desenvolvimento de "baixo para cima", a partir da convergência do crescimento econômico regional que elaborou o conceito de capital social (WILLIS, 2011) como um dos mais representativos nessa abordagem, e à contribuição do que Krugman (1991) denominou de "nova geografia econômica". Esta compreende os estudos recentes de fatores, como as externalidades pecuniárias e tecnológicas, redução do custo de transporte e dimensão do 
mercado, está relacionada com a tendência atual da concentração geográfica das atividades econômicas.

O capítulo 3, um dos mais importantes da obra dada a sistematização que o autor faz das teorias que envolvem as discussões de geografia da inovação dos últimos 30 anos, trata com mais aprofundamento das relaçôes entre território e inovação ao realizar uma análise do que Moulaert e Sekia (2003) denominam de territorial inovation models, que não devem ser considerados, como sugere a tradução literal, modelos de análises territoriais, mas sim um conjunto de análises teóricas sobre a relação entre território e inovação.

Assim, nesse capítulo, Mário Vale apresenta os argumentos de cada abordagem teórica, os autores mais importantes e as principais fragilidades teóricas e metodológicas dessas teorias. $\mathrm{O}$ autor analisa as seguintes perspectivas: novos espaços industriais de autores como Scott (1988) e Storper (1997); clusters de Porter (1990) e Saxenian (1994); a recuperação do conceito marshaliano de distrito industrial a partir das análises recentes de Antonelli (1999), Amin (1992), Becattini (1992), entre outros; o meio inovador de autores como Aydalot (1986), Camagni (1991), Maillat (1982) que estão associados ao Groupe de Recherche Européen sur lềs Milieux Innovateurs (GREMI) na Suíça; e os sistemas regionais e nacionais de inovação de Cooke (1992), Florida (1995) e Freeman (2002).

O capítulo 4, que tem como título "Espaço, redes de conhecimento e inovação" traz uma crítica sobre as teorias que analisam as redes de cooperação entre empresas e instituições de apoio, a partir da visão dual de proximidade versus distância. $\mathrm{O}$ autor parte dos conceitos de conhecimento codificado e conhecimento tácito, já citados anteriormente, para mostrar que hoje as redes de cooperação estabelecidas entre empresas e instituições de apoio na dinâmica da inovação não podem mais ser analisadas de forma excludente e que ambas, as redes próximas e distantes, são essenciais para as empresas inovarem.

No último capítulo do livro, o autor aborda a dimensão institucional da inovação a partir da análise do papel de institutos regionais portugueses no apoio à troca e à exploração de diferentes tipos de conhecimentos. As instituições regionais analisadas são os institutos de ciência e tecnologia, agências de formação, associações empresariais e organizações financeiras de capital de risco.

Enfim, a obra é uma importante contribuição teórica e metodológica para os estudos que tratam da relação entre território e inovação em uma perspectiva geográfica, originando o que se denomina de geografia da inovação. Para isso, o autor recupera vários estudos da geografia, sociologia, economia e história, avançando 
na compreensão da economia do conhecimento - objeto de extensa bibliografia no Brasil em outras áreas do conhecimento, mas raro em estudos sobre geografia brasileira -, a partir de uma perspectiva em que o território, conceito fundamental da geografia, é protagonista do desenvolvimento.

\section{Referências}

AMIN, A. Neo-marshallian nodes in global networks. International Journal of Urban and Regional Research, v. 23, n. 2, p. 365-378, 1992.

ANTONELLI, C. The evolution of the industrial organisation of the production of knowledge. Cambridge Journal of Economics, v. 23, n. 2, p.243-260, 1999.

AYDALOT, P. Milieux innovateurs em Europe. Paris: Gremi, 1986.

BECATTINI. G. Le district marshalien: une notion socio-économique. In: BENKO, G.; LIPIETZ, A. Les régions qui gagnent. Districts et réseaux: les nouveaux paradigmes de la géographie économique. Paris: Presses Universitaires de France, 1992, p. 35-55.

CAMAGNI, R. Innovation networks. Spacial perspectives. London: Belhaven Press, 1991.

COOKE, P. Regional innovation systems: competitive regulation in the new Europe. Geoforum, v. 23, n. 3, p. 365-382, 1992.

FLORIDA, R. Toward the learning region. Futures, v. 27, n. 5, p. 527-536, 1995.

FREEMAN, C. Continental, national and sub-national innovation systems-complementarity and economic growth. Research Policy, v. 31, n. 2, p. 191-211, 2002.

HAGERSTRAND, T. Innovation diffusion as a spatial process. Chicago: University Chicago Press, 1967.

HARVEY, D. The limits to capital. London: Verso, 2007.

KRUGMAN, P. Geography and trade. Cambridge: MIT Press, 1991. MAILLAT, D. Technology: a key factor for regional development. Saint-Saphorin: Editions Georgi, 1982.

MOULAERT, F.; SEKIA, F. Territorial innovation models: a critical survey. Regional Studies, v. 37, n. 3, p.289-302, 2003. 
RESENHA

PORTER, M. the competitive advantage of nations. London: Macmillan, 1990.

SAXENIAN, A. Regional advantage. Cambridge: Harvard University Press, 1994.

SCHUMPETER, J. Theory of economic development. Cambridge: Harvard University Press, 1911.

SCOTT, A. J. New industrial spaces. London: Pion, 1988.

STORPER, M. The Regional World. Territorial foundations and social regulation of flexible production complexes. In WOLCH, J.; DEAR, M. (Orgs.). The power of geography. How territory shapes social life. London: Allen and Unwin, 1997, p.21-40.

WALLERSTEIN, I. The modern world system. New York: Academic Press, 1974.

WILLIS, K. Theories and practices of development. London: Routledge, 2011. 